\title{
MicroRNA-375 overexpression influences P19 cell proliferation, apoptosis and differentiation through the Notch signaling pathway
}

\author{
LIHUA WANG $^{1 *}$, GUIXIAN SONG ${ }^{2 *}$, MING LIU $^{3}$, BIN CHEN $^{3}$, YUMEI CHEN $^{3}$, \\ YAHUI SHEN ${ }^{4}$, JINGAI ZHU ${ }^{4}$ and XIAOYU ZHOU ${ }^{1}$ \\ ${ }^{1}$ Department of Neonatology, Nanjing Children's Hospital, Affiliated to Nanjing Medical University, Nanjing, Jiangsu 210029; \\ ${ }^{2}$ Department of Cardiology, Taizhou People's Hospital, Taizhou, Jiangsu 225300; ${ }^{3}$ Department of Cardiology, \\ The First Affiliated Hospital of Nanjing Medical University; ${ }^{4}$ Department of Children Health Care, \\ Nanjing Maternity and Child Health Care Hospital Affiliated to Nanjing Medical University, \\ Nanjing, Jiangsu 210029, P.R. China
}

Received March 13, 2015; Accepted September 30, 2015

DOI: 10.3892/ijmm.2015.2399

\begin{abstract}
Our previous study reported that microRNA-375 (miR-375) is significantly upregulated in ventricular septal myocardial tissues from 22-week-old fetuses with ventricular septal defect as compared with normal controls. In the present study, the specific effects of miR-375 on P19 cell differentiation into cardiomyocyte-like cells were investigated. Stable P19 cell lines overexpressing miR-375 or containing empty vector were established, which could be efficiently induced into cardiomyocyte-like cells in the presence of dimethyl sulfoxide in vitro. miR-375 overexpression was verified using reverse transcription-quantitative polymerase chain reaction (RT-qPCR). Cell proliferation was determined according to total cell counts; cell cycle distribution and apoptosis levels were examined using flow cytometry. Apoptosis-related morphological changes were observed using Hoechst staining and fluorescence microscopy. During P19 cell differentiation, the cardiomyogenesis-related mRNAs (cardiac troponin T, GATA binding protein 4, myocyte-specific enhancer factor 2C) and mRNAs involved in the Notch signaling pathway (Notch2, Delta-like 1 and hes family bHLH transcription factor 1) were detected at days $0,4,6$ and 10 . Their differential expression was examined using RT-qPCR; the apoptosis-related genes
\end{abstract}

Correspondence to: Mrs. Xiaoyu Zhou, Department of Neonatology, Nanjing Children's Hospital, Affiliated to Nanjing Medical University, Nanjing, Jiangsu 210029, P.R. China

E-mail: xyzhou161@163.com

Mrs. Jingai Zhu, Department of Children Health Care, Nanjing Maternity and Child Health Care Hospital Affiliated to Nanjing Medical University, Nanjing, Jiangsu 210029, P.R. China

E-mail: zhujingai1983@163.com

*Contributed equally

Key words: microRNA-375, P19 cells, proliferation, apoptosis, differentiation, Notch signaling pathway
$B A X$ and $B c l-2$ were also detected using this method. The corresponding proteins were evaluated by western blotting. Compared with the control group, miR-375 overexpression inhibited proliferation but promoted apoptosis in P19 cells, and the associated mRNAs and proteins were decreased during differentiation. miR-375 has an important role in cardiomyocyte differentiation, and can disrupt this process via the Notch signaling pathway. The present findings contribute to the understanding of the mechanisms of congenital heart disease and facilitate the development of new gene therapies.

\section{Introduction}

The heart is one of the most frequently studied human organs and is the organ most susceptible to disease. Congenital heart defects (CHD), the most common of the human birth defects, occur in nearly $1 \%$ of the population worldwide $(1,2)$. Significant progress in CHD treatment has occurred over the years; consequently, more patients with CHD live to adulthood, creating a new and steadily growing patient population. These patients require long-term expert medical care and healthcare, which is expensive $(3,4)$. Correspondingly, the global health burden resulting from CHD has rapidly increased. However, CHD progresses to degenerative conditions that subsequently afflict CHD survivors. The developmental process of the heart is complicated, involving a series of genes and multiple signaling pathways (Notch, bone morphogenetic protein and transforming growth factor- $\beta)(5,6)$; a small mutation in any of these genes or pathways will result in embryonic heart defects.

MicroRNAs (miRNAs or miRs) are endogenous 18-22-nucleotide RNAs that have important regulatory roles in animals and plants by targeting mRNAs for cleavage or translational repression $(7,8)$. Currently, numerous aspects of miRNA function in animals, including their involvement in cell proliferation, apoptotic events, differentiation, fat and lipid metabolism, cancer, diabetes, and other diseases, have been researched and established $(9,10)$. It is becoming evident that miRNAs are involved in different aspects of cardiomyogenesis $(11,12)$, and have recently been demonstrated to serve 
as diagnostic biomarkers $(13,14)$. Based on these findings, prenatal detection of fetal CHD was performed in our previous studies, identifying that miRNA-375 (miR-375) is significantly upregulated in maternal serum at 18-22 weeks of gestation with fetal CHD $(15,16)$, indicating that it may be involved in the occurrence or development of CHD. Using bioinformatics analysis, the downstream target genes of miR-375 were predicted, which predicted mediation of Notch2, a key protein in the Notch signaling pathway.

Notch signaling is an evolutionarily conserved pathway that controls cell fate in metazoans through local cell-cell interactions. In canonical Notch signaling, transmembrane receptors (Notch1-4) bind with transmembrane ligands [Jagged1, Jagged2, Delta-like 1 (Dll1), Dll3 and D114] through their extracellular domains on adjacent cells, initiating proteolysis of the receptors and subsequent release of the signal-transducing Notch intracellular domain (NICD). NICD subsequently translocates to the nucleus and associates with the nuclear proteins of the recombination signal binding protein for the immunoglobulin kappa $\mathbf{J}$ region (RBP-Jk) family [also known as CSL or $\mathrm{CBF} 1 / \mathrm{Su}(\mathrm{H}) / \mathrm{Lag}-1]$ to assemble a transcription complex, which activates the expression of the target genes of Notch signaling, such as the HES and homocysteine-induced endoplasmic reticulum protein families (17-19). Notch signaling has an essential role in cardiac cell differentiation $(20,21)$. We hypothesized that miR-375 may influence heart development through the Notch signaling pathway, however, the detailed mechanism requires elucidation. The present study explored the role of miR-375 in cardiogenesis in vitro, which may occur via the Notch signaling pathway.

\section{Materials and methods}

P19 cell culture and induction of differentiation. P19 cells were obtained from the American Type Culture Collection (Manassas, VA, USA) and cultivated as aggregates for 4 days in Minimum Essential Medium $\alpha$-modification ( $\alpha$-MEM) containing $10 \%$ fetal bovine serum (FBS) (Gibco-BRL; Thermo Fisher Scientific, Grand Island, NY, USA) and 1\% dimethyl sulfoxide (DMSO; Sigma-Aldrich, St. Louis, MO, USA) in bacteriological dishes in $5 \% \mathrm{CO}_{2}$ at $37^{\circ} \mathrm{C}$. After 4 days of aggregation, the cell clusters were transferred to culture flasks in $\alpha$-MEM with $10 \%$ FBS. The medium was replaced every 2 days. Cells were harvested at differentiation days 0,4 , 6 and 10. The cell morphological changes were observed and images were captured using an inverted microscope (Nikon, Tochigi, Japan).

Establishment of miR-375-overexpressing P19 cell lines. Plasmids overexpressing miR-375 and negative control vectors contained enhancing green fluorescence protein (GFP) and were constructed by GenePharma (Shanghai, China). Briefly, partial primary transcript sequences for the mouse miR-375 genes were amplified from embryonic telencephalon cDNA and cloned into pcDNA ${ }^{\mathrm{TM}}$ 6.2-GW/EmGFPmiR (Promega, Madison, WI, USA). miRNA transfection was performed with Lipofectamine 2000 (Invitrogen, Carlsbad, CA, USA) according to the manufacturer's protocol. Fluorescence microscopy was used to observe the transfection efficiency via GFP expression of the miR-375 expression vector and control vector in P19 cells. miR-375 expression was verified using reverse transcription-quantitative polymerase chain reaction (RT-qPCR). All the data were normalized to the internal standard (U6). Sequences for RT-qPCR primer pairs are listed as follows: mmu-miR-375 forward, AGCCGTTTGTTCGTT CGGCT and reverse primer, GTGCAGGGTCCGAGGT; and U6 forward, CGCTTCGGCAGCACATATAC and reverse primer, TTCACGAATTTGCGTGTCAT.

\section{Cell proliferation assays}

Cell counting kit-8 (CCK-8) assay. To analyze the proliferation of the stable cell lines bearing miR-375 expression plasmids or vector, 2,000 cells/well in $100 \mu \mathrm{l}$ medium were seeded in 96-well plates subsequent to obtaining total cell counts using a hemocytometer, and were cultured in $\alpha$-MEM supplemented with $10 \% \mathrm{FBS}$ at $37^{\circ} \mathrm{C}$ with $5 \% \mathrm{CO}_{2}$. Cell viability was monitored at $0,24,36,48$ and $72 \mathrm{~h}$. At each time-point, each well was treated with $10 \mu \mathrm{l} \mathrm{CCK-8} \mathrm{(Dojindo,} \mathrm{Kumamoto,} \mathrm{Japan)}$ solution, and the optical density was measured $2 \mathrm{~h}$ later with a microplate reader at 450 and $650 \mathrm{~nm}$.

Cell cycle assay. Flow cytometry was used to evaluate the distribution of cells in different phases of the cell cycle following transfection, basing the evaluation on the DNA content of propidium iodide (PI)-stained nuclei (22). The cells were synchronized by culturing with serum-free $\alpha$-MEM for $24 \mathrm{~h}$. Subsequently, all the cells were digested with EDTA-free trypsin (Invitrogen), washed in phosphate-buffered saline (PBS), and centrifuged at 1,000 rpm for $5 \mathrm{~min}$. The supernatant was discarded and the pellets were fixed overnight at $4^{\circ} \mathrm{C}$ in cold $70 \%$ ethanol. Following this, the cells were washed with PBS and incubated with $100 \mathrm{mg} / \mathrm{ml}$ RNase A (Sigma-Aldrich) at $37^{\circ} \mathrm{C}$ for $1 \mathrm{~h}$, and incubated at $4^{\circ} \mathrm{C}$ in the dark for $30 \mathrm{~min}$ with $100 \mu \mathrm{g} / \mathrm{ml}$ PI (Sigma-Aldrich). Disposed cells were analyzed using a BD FACScan system and CellQuest software (BD Biosciences, San Jose, CA, USA).

\section{Analysis of apoptosis}

Hoechst staining. The apoptosis rate in the transfected cells was first evaluated by Hoechst staining. Briefly, cells were seeded on sterile cover glasses in 6-well plates the day before treatment. Subsequently, the cells were fixed, washed twice with PBS, and stained with Hoechst 33258 (apoptosis Hoechst staining kit; Beyotime Institute of Biotechnology, Jiangsu, China) according to the manufacturer's protocol. The stained cells were examined and immediately images were captured under a fluorescence microscope (Nikon).

Flow cytometry. Cells were cultured in FBS-free $\alpha$-MEM (serum-free) for $24 \mathrm{~h}$ to induce apoptosis, and were harvested with EDTA-free trypsin, washed in PBS, resuspended in $500 \mu \mathrm{l}$ binding buffer, and stained with $5 \mu \mathrm{l}$ Annexin V-allophycocyanine (Annexin V-APC) and $5 \mu 1$ 7-amino-actinomycin D (7-AAD) at room temperature for $10 \mathrm{~min}$ (Annexin V-APC/7-AAD Apoptosis Detection kit; KeyGen Biotech, Jiangsu, China). Disposed cells were analyzed using a BD FACScan system and CellQuest software (BD Biosciences).

$R T-q P C R$. Total RNA was isolated from cultured P19 cells using the TRIzol method (Invitrogen) with an miRNeasy mini kit (Qiagen, Limburg, The Netherlands). Complementary DNA was synthesized from $1 \mu \mathrm{g}$ total RNA using an AMV reverse 
Table I. Sequences of the primer sets used in the reverse transcription-quantitative polymerase chain reaction.

\begin{tabular}{lll}
\hline Gene & \multicolumn{1}{c}{ Forward primer $\left(5^{\prime}-3^{\prime}\right)$} & Reverse primer $\left(3^{\prime}-5^{\prime}\right)$ \\
\hline$c T n T$ & GGAGTACGAGGAGGAACAGG & GTCCACTCTCTCTCCATCGG \\
GATA4 & CCAACTGCCAGACTACCAC & GGACCAGGCTGTTCCAAGA \\
$N$ N $2 \mathrm{C} C H 2$ & CAGCACTGACATGGATAAGG & CTGCCAGGTGGGATAAGAACG \\
$D L L 1$ & GGTCGCTGTTGTCATCATCC & TGACACTTGCACGGAGAGAT \\
$H E S 1$ & CGATGAGTGTGCTAGCAACC & GCAGTGGTCTTTCAGGTGTG \\
$B A X$ & CAGTGCCTTTGAGAAGCAGG & CAGATAACGGGCAACTTCGG \\
$B C L-2$ & CCAGCCCATGATGGTTCTGAT & CCGGCGAATTGGAGATGAACT \\
$G A P D H$ & CAGACATGCACCTACCCAGC & GTCGCTACCGTCGTGACTTC \\
\hline
\end{tabular}

$c T n T$, cardiac troponin T; GATA4, GATA binding protein 4; MEF2C, myocyte enhancer factor 2C; DLL1, Delta-like 1; HES1, hes family bHLH transcription factor 1; $B C L-2$, B-cell chronic lymphocytic leukemia/lymphoma 2; GAPDH, glyceraldehyde-3-phosphate dehydrogenase.

transcriptase kit (Promega). RT-qPCR using the SYBR-Green method was performed using an ABI 7500 Sequence Detection System (Applied Biosystems, Foster City, CA, USA) according to the manufacturer's protocols. The PCR conditions involved a denaturation step $\left(95^{\circ} \mathrm{C}\right.$ for $\left.10 \mathrm{~min}\right)$, and amplification and quantification were repeated 40 times $\left(95^{\circ} \mathrm{C}\right.$ for $15 \mathrm{sec}$ and $60^{\circ} \mathrm{C}$ for $1 \mathrm{~min}$, respectively). The relative gene expression levels were quantified based on the threshold cycle $(\mathrm{Ct})$ and normalized to the reference gene glyceraldehyde-3-phosphate dehydrogenase $(G A P D H)$. Table I lists the primer sequences used.

Antibodies and western blotting. Anti-Notch2 (5732s), anti-Dll1 (2588s), anti-hes family bHLH transcription factor 1 (Hes1; 11988s), and anti-GAPDH antibodies were purchased from Cell Signaling Technology (Danvers, MA, USA). GATA binding protein 4 (GATA4; BS1747), myocyte enhancer factor 2C (Mef2c; BS6401), and cardiac troponin T (cTnT/TNNT2; BS6013) were purchased from Bioworld Technology Inc. (St. Louis Park, MN, USA). The antibodies used were all specific monoclonal antibodies. GAPDH was used as the internal reference. Lysis buffer [1\% Triton X-100, $50 \mathrm{mmol} / \mathrm{l}$ Tris-HCl, $0.2 \%$ sodium dodecyl sulfate, $0.2 \%$ sodium deoxycholate, $1 \mathrm{mmol} / \mathrm{l}$ EDTA (pH 7.4)] was directly added to the cultured cells, which were subsequently transferred into tubes and vortexed briefly. The supernatant was collected after centrifugation at 15,200 x g for $15 \mathrm{~min}$ at $4^{\circ} \mathrm{C}$. Protein concentrations were detected using a Bicinchoninic Acid Protein assay kit (Beyotime Institute of Biotechnology).

Luciferase reporter gene assay. The 3' untranslated region (3'UTR) sequences of the Notch 2 gene containing the predicted miR-375 binding site or a mutant seed sequence were termed W.T.Notch2-3'UTR and M.T.Notch2-3'UTR, respectively. In the luciferase assays, P19 cells cultured in 96-well plates were transiently transfected with either the W.T.Notch2-3'UTR or M.T.Notch2-3'UTR vector, along with the miR-375 overexpression plasmid using Lipofectamine 2000, according to the manufacturer's protocol. A Dual-Luciferase Reporter assay system (Promega) was used to analyze the luciferase activity after 48-h transfection.
Statistical analysis. Each experiment was performed at least three times. All the results are presented as the mean \pm standard deviation. Data were analyzed using t- or t'-test with correction for multiple comparisons as appropriate. $\mathrm{P}<0.05$ was considered to indicate a statistically significant difference.

\section{Results}

miR-375 expression in P19 cells. Plasmids overexpressing miR-375 and the negative vectors were transfected into P19 cells that were $70-80 \%$ confluent. Transfection efficiency was observed after 24 and $48 \mathrm{~h}$ via the expression of GFP under a fluorescence microscope (Fig. 1A). miR-375 expression in the two groups was confirmed by RT-qPCR $(\mathrm{P}<0.01)$ (Fig. 1B). At day 7 during differentiation, spontaneous contraction of the myocardium-like cell clusters was observed occasionally. Cluster contraction increased over the subsequent days, and peaked at around day 12 (data not shown).

miR-375 overexpression inhibits cell proliferation. The proliferation rate of $\mathrm{P} 19$ cells overexpressing miR-375 was evaluated using the CCK-8 assay. Compared with the control group, continuous 72-h monitoring determined that proliferation was reduced in the miR-375 overexpression group $(\mathrm{P}<0.05$ and $\mathrm{P}<0.01$ ) (Fig. 2A). miR-375 also influenced the cell cycle: Flow cytometry revealed a decreased percentage of $\mathrm{S}$ phase cells in the miR-375 overexpression group in contrast to the control group $(\mathrm{P}<0.05)$ (Fig. 2B).

miR-375 overexpression promotes apoptosis. Hoechst staining is a classic, quick and easy method for distinguishing apoptotic cells from normal cells. As the chromatin condenses during apoptosis, Hoechst staining would have rendered it clearly visible in the nuclei of cells overexpressing miR-375, where it was visible as condensed, brighter spots under fluorescence microscopy, whereas normal cells appeared more homogenously stained (Fig. 3A). By contrast, flow cytometry assessment of apoptosis revealed higher apoptotic rates in cells overexpressing miR-375 compared to the controls $(\mathrm{P}<0.01$; UL, upper left; UR, upper right; LL, lower left; LR, lower right. 
A
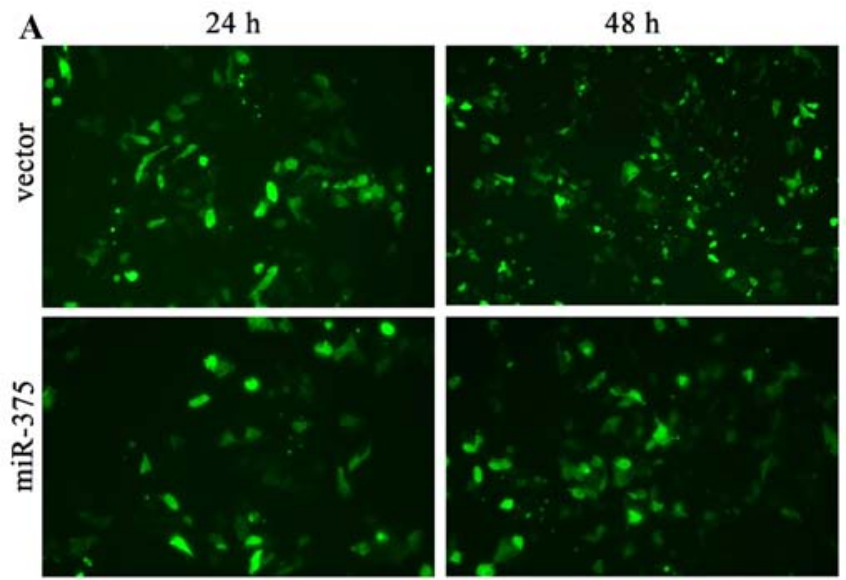

B

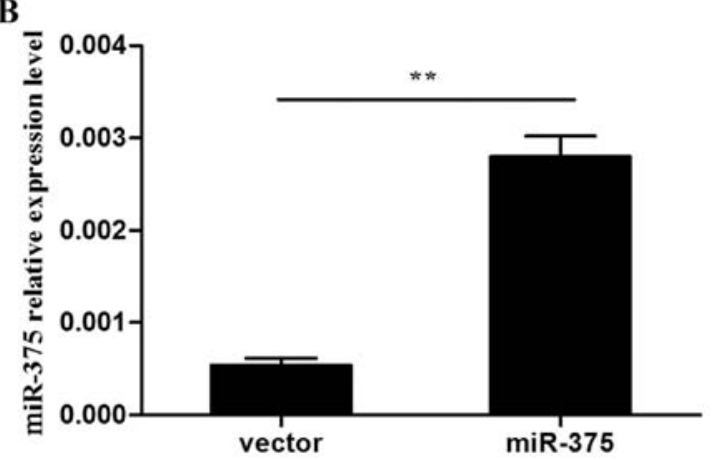

Figure 1. miR-375 expression in P19 cells. (A) Fluorescence microscopy images of transfection efficiency of the miR-375 overexpression vector and control vector in P19 cells determined via green fluorescence protein expression. (B) Reverse transcription-quantitative polymerase chain reaction verification of miR-375 expression. Data were normalized to the level of U6 RNA in each sample. Data are the mean \pm standard deviation of three experiments, ${ }^{* *} \mathrm{P}<0.01$.

The apoptotic rate was calculated by UR+LR (Fig. 3B-a). In addition, RT-qPCR detected the apoptosis-related genes $\mathrm{Bax}$ and B-cell chronic lymphocytic leukemia/lymphoma 2 (Bcl-2) following 24-h culture in serum-free $\alpha$-MEM for inducing apoptosis. By calculating the $\mathrm{Bax} / \mathrm{Bcl}-2$ ratio, the apoptosis rate was observed to be increased following miR-375 overexpression; the $\mathrm{Bax}$ and $\mathrm{Bcl}-2$ protein levels were consistent with their mRNA expression levels $(\mathrm{P}<0.01)$ (Fig. 3C).

Effect of miR-375 on P19 cell differentiation. The process by which P19 cells were induced into cardiomyocytes was observed using an inverted microscope. P19 cells underwent a series of morphological changes (Fig. 4A). At day 4, the generated cell bodies in the control group were larger and rounder than those in the miR-375 overexpression group. Similarly, at day 10 , the condition of cells in the control group was improved compared to that in the miR-375 overexpression group. At days 0, 4, 6 and 10 of differentiation, the differential mRNA expression of the myocardial-specific marker genes $c T n T, G A T A 4$ and MEF2C was determined using RT-qPCR. The corresponding mRNA levels were barely detectable in the undifferentiated P19 cells, but their expression was rapidly upregulated following DMSO induction. However, there was a negative effect on P19 cell differentiation into cardiomyocytes in the miR-375 overexpression group compared to the control
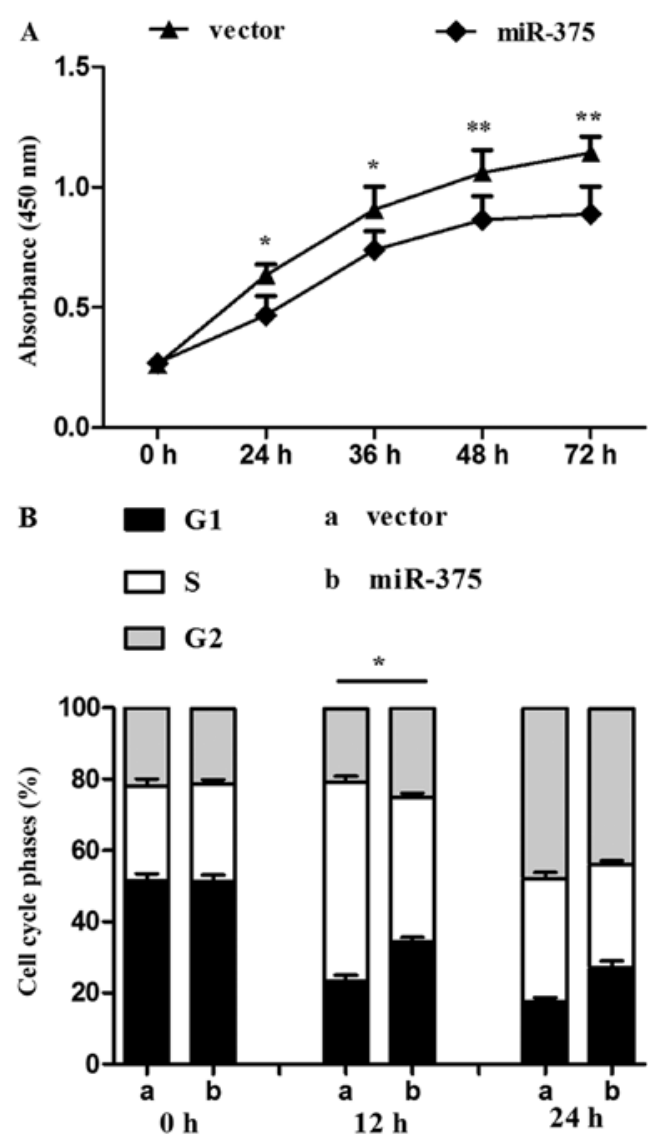

Figure 2. miR-375 overexpression inhibits cell proliferation. (A) Cell proliferation was continuously monitored for $72 \mathrm{~h}$ using the cell counting kit-8 (CCK-8). (B) Flow cytometry assessment of differential cell cycle stages. CCK-8 and flow cytometry showed that miR-375 overexpression inhibited P19 cell proliferation. Data are the mean \pm standard deviation of three experiments, ${ }^{*} \mathrm{P}<0.05$ and ${ }^{* *} \mathrm{P}<0.01$.

group $(\mathrm{P}<0.05$ and $\mathrm{P}<0.01)$ (Fig. 4B). The relative protein levels detected by western blotting verified the trend $(\mathrm{P}<0.05$ and $\mathrm{P}<0.01$ ) (Fig. $4 \mathrm{C}$ and $\mathrm{D}$ ).

Effect of miR-375 on the Notch signaling pathway. As NOTCH2 was a predicted downstream target gene of miR-375, further verification and discussion was necessary. The 3'UTR of NOTCH2 was confirmed as a target of miR-375. As expected, miR-375 inhibited the luciferase activity of the W.T.Notch2-3'UTR reporter efficiently, but not that of the M.T.Notch2-3'UTR $(\mathrm{P}<0.01)$ (Fig. 5A). The mRNA expression levels of the pivotal Notch signaling pathway regulators NOTCH 2, DLL1 and HES1 were detected by RT-qPCR, and were significantly decreased in the miR-375 overexpression group at the examined time-points compared to that of the control group $(\mathrm{P}<0.05$ and $\mathrm{P}<0.01)$ (Fig. 5B). The associated protein levels were detected using western blotting (Fig. 5C) and their relative levels were calculated $(\mathrm{P}<0.05$ and $\mathrm{P}<0.01$ ) (Fig. 5D). All data indicated an inhibitory effect of miR-375 on the Notch signaling pathway.

\section{Discussion}

The present study observed that miR-375 promoted apoptosis and inhibited cell proliferation and differentiation. Notch2 


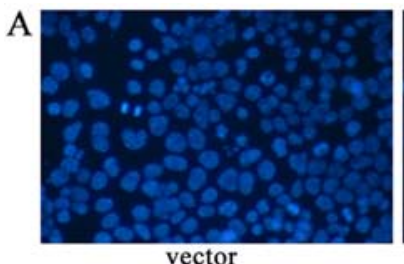

B a

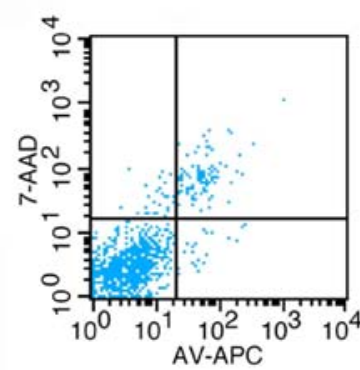

vector

\begin{tabular}{rc} 
Quad $\%$ Gated \\
\hline UL $\quad 3.08$
\end{tabular}

UR $\quad 11.50$

LL $\quad 82.79$

LR $\quad 2.62$

C

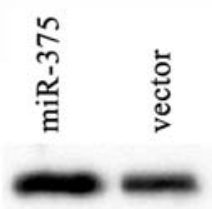

Bax

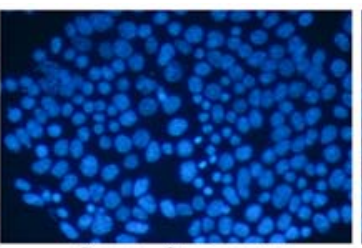

Serum-free vector

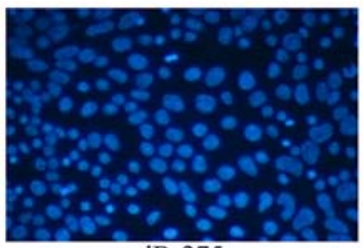

miR-375

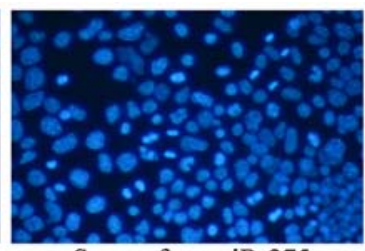

Serum-free miR-375

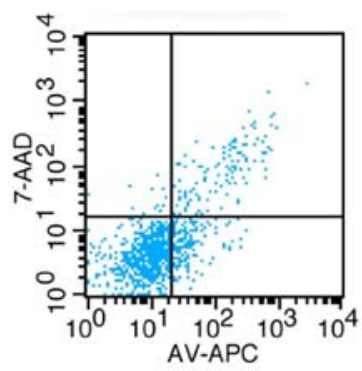

b

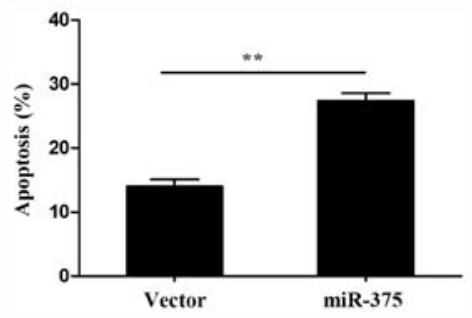

miR-375

\begin{tabular}{cr} 
Quad $\%$ Gated \\
\hline UL
\end{tabular}

UR $\quad 9.89$

LL $\quad 69.75$

LR $\quad 18.33$

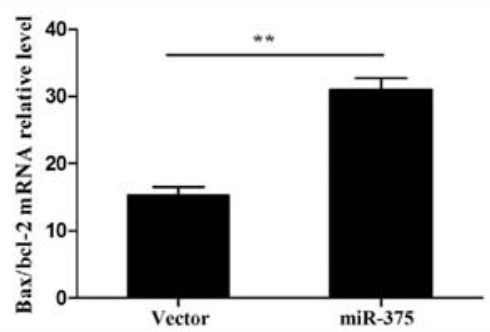

Figure 3. miR-375 overexpression promotes apoptosis. (A) The effect of miR-375 on cellular morphology was detected using Hoechst staining under fluorescence microscopy (magnification, x200). (B) (a) Cells were cultured in serum-free of Minimum Essential Medium $\alpha$-modification for $24 \mathrm{~h}$ to induce apoptosis Apoptosis was assayed by binding of Annexin V-allophycocyanine (AV-APC). Flow cytometry was used to assess the apoptotic rate. (B) (b) Representative data from three independent experiments are shown. (C) Effects of miR-375 on Bax and Bcl-2 protein and mRNA expression levels in P19 cells. The Bax/Bcl-2 ratio represents the apoptotic rate. Data are normalized to U6 and presented as the mean \pm standard deviation of three experiments, ${ }^{*} \mathrm{P}<0.05$ and ${ }^{* *} \mathrm{P}<0.01$.

was also confirmed as a target gene of miR-375, and miR-375 overexpression significantly influenced other vital members of the Notch signaling pathway. As miR-375 has been identified from the ventricular septal myocardial tissues from fetuses with ventricular septal defects, the present findings may shed light on novel therapeutic methods for CHD.

As the number of adults who have survived CHD is gradually increasing, CHD is currently becoming a significant health issue worldwide. Despite various treatments, the high incidence and serious resultant complications render CHD one of the leading causes of morbidity and mortality $(23,24)$. Therefore, determining its pathogenesis and devising useful therapies is urgent. In recent years, it was determined that miRNAs are responsible for CHD (25), providing insight into how they may be exploited to understand and study the mechanism of this disease, as well as identifying them as promising candidates for potential novel treatment strategies.

miR-375 regulates insulin secretion, pancreatic islet development and alveolar epithelial cell transdifferentiation (26-28). Our previous study determined that miR-375 is abundantly expressed in the developing heart with consistent fold changes (29). In addition, miR-375 is significantly upregulated in maternal serum at $18-22$ weeks of gestation with fetal CHD (15). These results demonstrate that miR-375 is associated with heart development and is involved in the occurrence of CHD. However, the specific mechanism remains unknown.

The present results show that miR-375 overexpression promotes apoptosis and inhibits cell proliferation and differentiation. The CCK- 8 assay and decreased percentage of $\mathrm{S}$ phase cells confirmed the negative effect of miR-375 on cell proliferation. Simultaneously, Hoechst staining illustrating clear morphological diversity accompanied by flow cytometry was used to assess the apoptosis rate, and indicated the promoting effect of miR-375 on apoptosis. In contrast to necrocytosis, apoptosis is a process that involves cellular gene expression. Subsequently, the apoptosis-related genes $B A X$ and $B C L-2$ were examined, and the $\mathrm{Bax} / \mathrm{Bcl}-2$ ratio in the miR-375 overexpression group was increased, which did not contradict our previous findings. Bax and Bcl-2 are members of the Bcl-2 family, which is a pivotal regulator of apoptosis (30). The Bcl-2 family contains pro-apoptotic (Bax, Bak, Bad and Bcl-xS) and anti-apoptotic (Bcl-2 and Bcl-xL) members. It is believed that the $B C L-2$ gene product inhibits cell death and contributes to the prolongation of cell survival, 

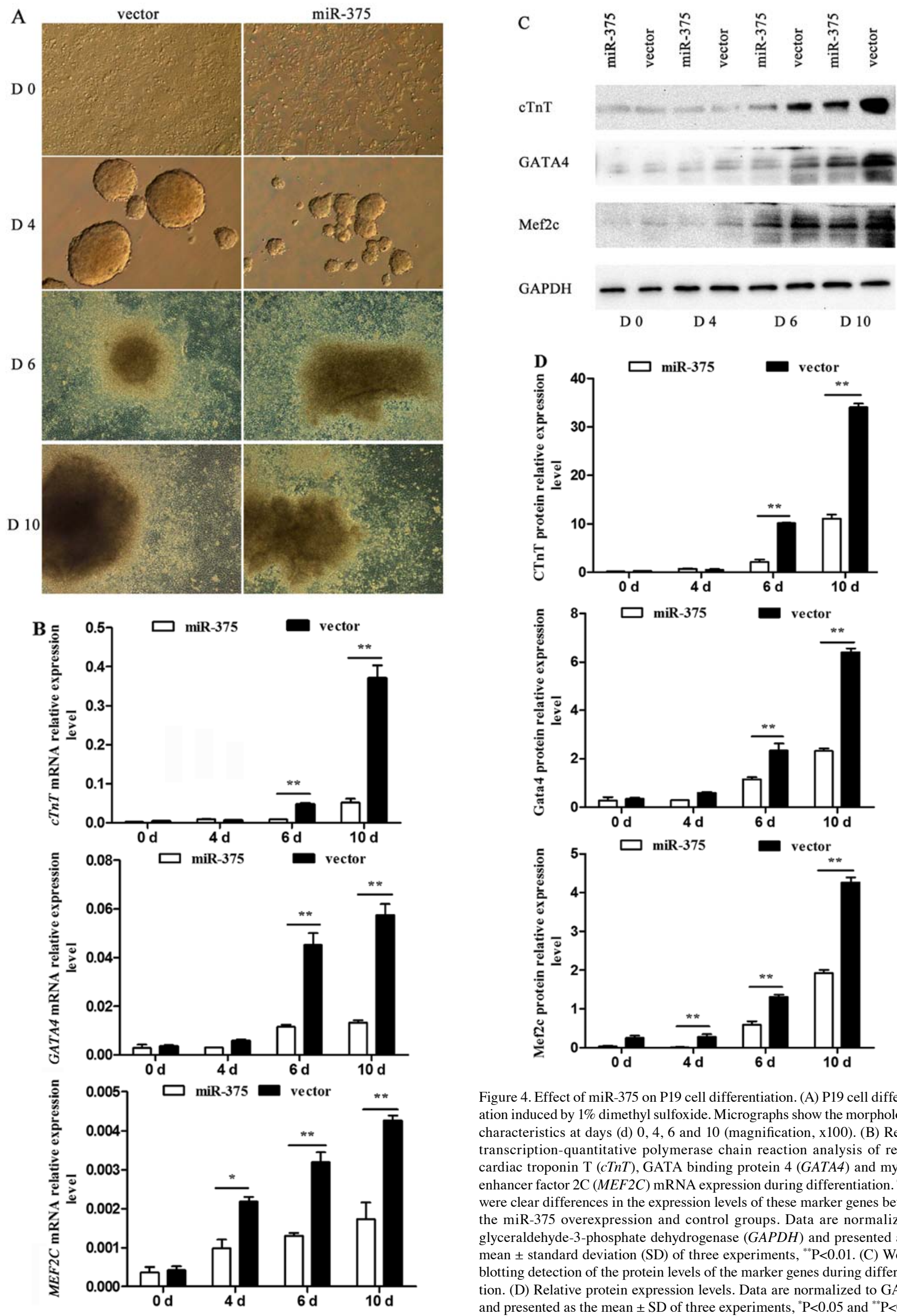

Figure 4. Effect of miR-375 on P19 cell differentiation. (A) P19 cell differentiation induced by $1 \%$ dimethyl sulfoxide. Micrographs show the morphological characteristics at days (d) 0, 4, 6 and 10 (magnification, x100). (B) Reverse transcription-quantitative polymerase chain reaction analysis of relative cardiac troponin $\mathrm{T}(c T n T)$, GATA binding protein 4 (GATA4) and myocyte enhancer factor $2 \mathrm{C}(M E F 2 C) \mathrm{mRNA}$ expression during differentiation. There were clear differences in the expression levels of these marker genes between the miR-375 overexpression and control groups. Data are normalized to glyceraldehyde-3-phosphate dehydrogenase $(G A P D H)$ and presented as the mean \pm standard deviation (SD) of three experiments, ${ }^{* *} \mathrm{P}<0.01$. (C) Western blotting detection of the protein levels of the marker genes during differentiation. (D) Relative protein expression levels. Data are normalized to GAPDH and presented as the mean \pm SD of three experiments, ${ }^{*} \mathrm{P}<0.05$ and ${ }^{* * *} \mathrm{P}<0.01$. 

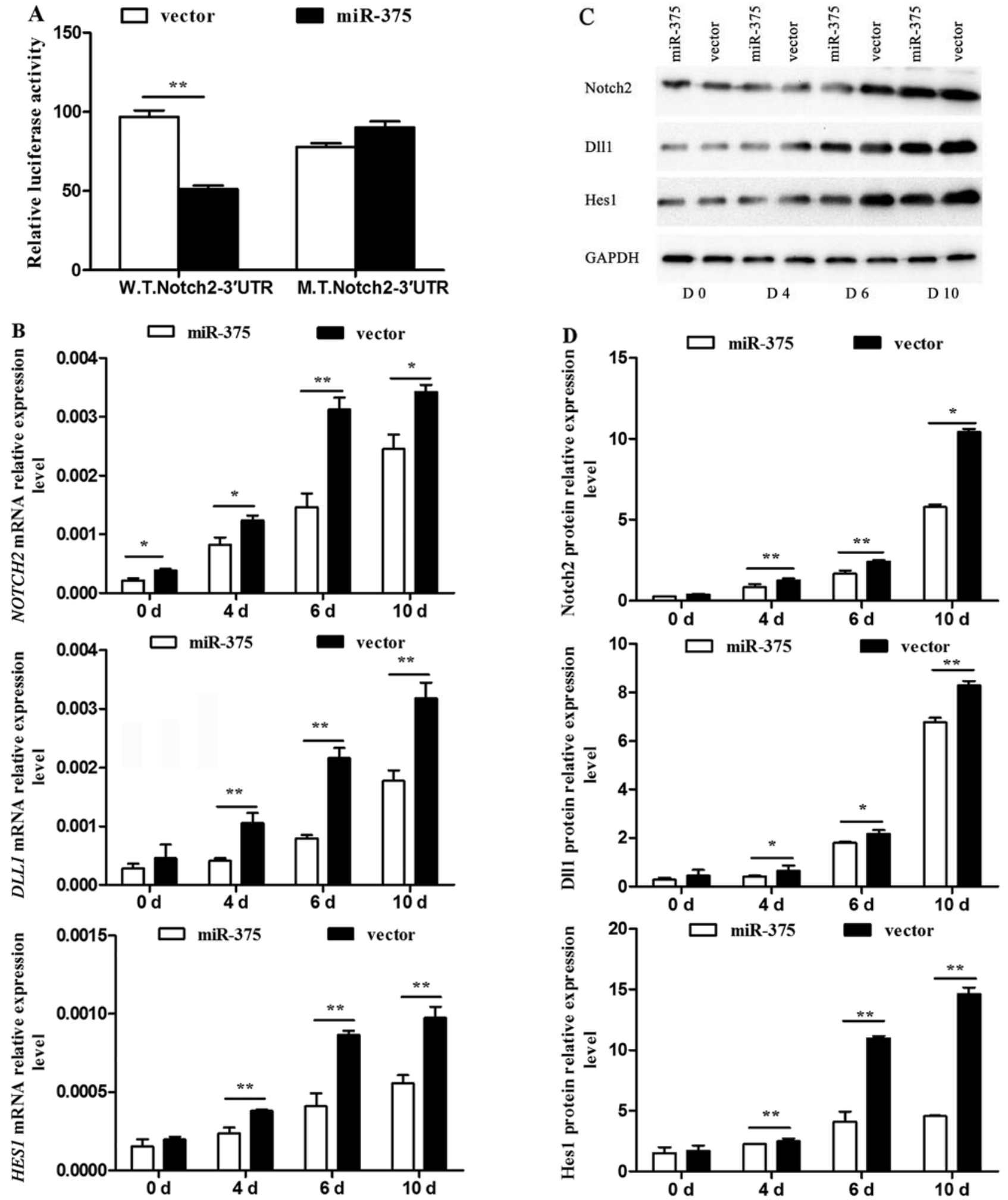

Figure 5. Effect of miR-375 on the Notch signaling pathway. (A) Luciferase reporter gene assay verification of the bioinformatics analysis-predicted NOTCH2 as a target gene of miR-375, ${ }^{* *} \mathrm{P}<0.01$. (B) NOTCH2, Delta-like 1 (DLL1) and hes family bHLH transcription factor 1 (HES1) mRNA expression levels detected by reverse transcription-quantitative polymerase chain reaction and normalized to GAPDH. Data are the mean \pm standard deviation (SD) of three experiments, ${ }^{*} \mathrm{P}<0.05$ and ${ }^{* *} \mathrm{P}<0.01$. (C) Western blotting demonstrating the inhibitory effect of miR-375 on the Notch signaling pathway. (D) Relative protein expression levels. Data are the mean $\pm \mathrm{SD}$ of three experiments, ${ }^{*} \mathrm{P}<0.05$ and ${ }^{* *} \mathrm{P}<0.01$.

while Bax, an important homologue of Bcl-2, is a promoter of apoptosis $(31,32)$. Evidently, the Bax/Bcl-2 ratio has a decisive role in cell fate. As aforementioned, the increased $\mathrm{Bax} / \mathrm{Bcl}-2$ ratio and relative protein levels in the present study demonstrate that miR-375 overexpression promotes apoptosis. Cell proliferation and apoptosis are basic features of living organisms; homeostasis of the two is an important biological activity for maintaining structural stability and environmental 
functional balance in multicellular organisms. Therefore, the inhibition of proliferation and promotion of apoptosis in miR-375 overexpression P19 cells shows that miR-375 influences P19 cell differentiation into cardiomyocytes and has a critical role during this process.

In addition, the effects of miR-375 were examined on P19 cell differentiation into cardiomyocytes. Murine P19 embryonal carcinoma cells, which can be induced by DMSO to differentiate into spontaneously beating cardiomyocytes in vitro $(33,34)$, are the classic model for investigating heart development and are a valuable means of studying cardiomyocyte differentiation. Over the years, several influencing factors associated with cardiac disease have been explored (35-37), which is an essential part of the present study. The RT-qPCR and western blotting data also demonstrate the reliability of this cell model. The relative expression levels of cTnT, GATA4 and Mef2c mRNA and protein exhibited an increase during differentiation.

Evolutionarily, the embryonic heart undergoes a series of complicated morphogenetic and differentiation processes prior to forming the mature cardiac structures during development. Notably, these processes are controlled by a conserved network of genes and signaling pathways (38-40), including the Notch signaling pathway. During mammalian cardiogenesis, Notch signaling is involved in the development of the aortic valve, ventricles, atrioventricular canal and outflow tract (41). Mutations in the Notch signaling components affect heart development and are eventually involved in several types of CHD (42). Jagged1 and Notch2 are involved in Alagille syndrome, an autosomal dominant genetic disorder that results in pulmonary artery stenosis and tetralogy of Fallot $(43,44)$. Notch1 is associated with aortic valve disease (45). Notably Notch signaling facilitates repair following myocardial injury by promoting myocardial regeneration, protecting the myocardium from ischemia, inducing angiogenesis, and inhibiting the transformation of cardiac fibroblasts to myofibroblasts (46). The present study used luciferase reporter gene assays to verify the downstream target genes predicted by bioinformatics analysis, and identified that miR-375 combined with the 3'UTR of NOTCH2, a key gene in the Notch signaling pathway. Furthermore, NOTCH2, DLL1 and HES1 mRNA levels were increased significantly during P19 cell differentiation in the control group, whereas this was not the case in the miR-375 overexpression group; the same trend was observed for the associated protein levels. The present study demonstrates that the Notch signaling pathway is involved in P19 cell differentiation and that miR-375 overexpression leads to abnormal expression of downstream Notch signaling pathway genes.

In conclusion, miR-375 overexpression promotes cell apoptosis and inhibits proliferation and differentiation through the Notch signaling pathway, which may provide potential targets for therapeutic intervention in CHD.

\section{Acknowledgements}

The present study was supported by grants from the Jiangsu Province Natural Science Foundation of China (no. BK20130076) and the Natural Science Foundation of China (no. 81501262).

\section{References}

1. Hoffman JI and Kaplan S: The incidence of congenital heart disease. J Am Coll Cardiol 39: 1890-1900, 2002.

2. Srivastava D: Making or breaking the heart: From lineage determination to morphogenesis. Cell 126: 1037-1048, 2006.

3. Somerville J: Grown-up congenital heart disease - medical demands look back, look forward 2000. Thorac Cardiovase Surg 49: 21-26, 2001.

4. van der Linde D, Konings EE, Slager MA, Witsenburg M, Helbing WA, Takkenberg JJ and Roos-Hesselink JW: Birth prevalence of congenital heart disease worldwide: A systematic review and meta-analysis. J Am Coll Cardiol 58: 2241-2247, 2011.

5. Garside VC, Chang AC, Karsan A and Hoodless PA: Co-ordinating Notch, BMP, and TGF- $\beta$ signaling during heart valve development. Cell Mol Life Sci 70: 2899-2917, 2013.

6. High FA and Epstein JA: The multifaceted role of Notch in cardiac development and disease. Nat Rev Genet 9: 49-61, 2008.

7. Bartel DP: MicroRNAs: Genomics, biogenesis, mechanism, and function. Cell 116: 281-297, 2004.

8. Yates LA, Norbury CJ and Gilbert RJ: The long and short of microRNA. Cell 153: 516-519, 2013.

9. Gangaraju VK and Lin H: MicroRNAs: Key regulators of stem cells. Nat Rev Mol Cell Biol 10: 116-125, 2009.

10. Ambros V: The functions of animal microRNAs. Nature 431: 350-355, 2004.

11. Feng Y and Yu X: Cardinal roles of miRNA in cardiac development and disease. Sci China Life Sci 54: 1113-1120, 2011.

12. Thum T, Catalucci D and Bauersachs J: MicroRNAs: Novel regulators in cardiac development and disease. Cardiovasc Res 79: 562-570, 2008.

13. Kasinski AL and Slack FJ: Epigenetics and genetics. MicroRNAs en route to the clinic: Progress in validating and targeting microRNAs for cancer therapy. Nat Rev Cancer 11: 849-864, 2011.

14. Callegari E, Gramantieri L, Domenicali M, D'Abundo L, Sabbioni S and Negrini M: MicroRNAs in liver cancer: A model for investigating pathogenesis and novel therapeutic approaches. Cell Death Differ 22: 46-57, 2015.

15. Zhu S, Cao L, Zhu J, Kong L, Jin J, Qian L, Zhu C, Hu X, Li M, Guo X, et al: Identification of maternal serum microRNAs as novel non-invasive biomarkers for prenatal detection of fetal congenital heart defects. Clin Chim Acta 424: 66-72, 2013.

16. Yu Z, Han S, Hu P, Zhu C, Wang X, Qian L and Guo X: Potential role of maternal serum microRNAs as a biomarker for fetal congenital heart defects. Med Hypotheses 76: 424-426, 2011.

17. Andersson ER, Sandberg R and Lendahl U: Notch signaling: Simplicity in design, versatility in function. Development 138 : 3593-3612, 2011.

18. Kopan R and Ilagan MXG: The canonical Notch signaling pathway: Unfolding the activation mechanism. Cell 137: 216-233, 2009.

19. Iso T, Kedes L and Hamamori Y: HES and HERP families: Multiple effectors of the Notch signaling pathway. J Cell Physiol 194: 237-255, 2003.

20. Chang ACY, Fu Y, Garside VC, Niessen K, Chang L, Fuller M, Setiadi A, Smrz J, Kyle A, Minchinton A, et al: Notch initiates the endothelial-to-mesenchymal transition in the atrioventricular canal through autocrine activation of soluble guanylyl cyclase. Dev Cell 21: 288-300, 2011.

21. Chau MDL, Tuft R, Fogarty K and Bao ZZ: Notch signaling plays a key role in cardiac cell differentiation. Mech Dev 123: 626-640, 2006.

22. Bishayee K, Ghosh S, Mukherjee A, Sadhukhan R, Mondal J and Khuda-Bukhsh AR: Quercetin induces cytochrome-c release and ROS accumulation to promote apoptosis and arrest the cell cycle in $\mathrm{G} 2 / \mathrm{M}$, in cervical carcinoma: Signal cascade and drug-DNA interaction. Cell Prolif 46: 153-163, 2013.

23. Verheugt CL, Uiterwaal CS, Grobbee DE and Mulder BJ: Long-term prognosis of congenital heart defects: A systematic review. Int J Cardiol 131: 25-32, 2008

24. Zomer AC, Vaartjes I, van der Velde ET, de Jong HM, Konings TC, Wagenaar LJ, Heesen WF, Eerens F, Baur LH, Grobbee DE, et al: Heart failure admissions in adults with congenital heart disease; risk factors and prognosis. Int J Cardiol 168: 2487-2493, 2013.

25. Sayed AS, Xia K, Salma U, Yang T and Peng J: Diagnosis, prognosis and therapeutic role of circulating miRNAs in cardiovascular diseases. Heart Lung Circ 23: 503-510, 2014. 
26. El Ouaamari A,Baroukh N,Martens GA,Lebrun P,Pipeleers D and van Obberghen E: miR-375 targets 3'-phosphoinositide-dependent protein kinase-1 and regulates glucose-induced biological responses in pancreatic beta-cells. Diabetes 57: 2708-2717, 2008.

27. Kloosterman WP, Lagendijk AK, Ketting RF, Moulton JD and Plasterk RH: Targeted inhibition of miRNA maturation with morpholinos reveals a role for miR-375 in pancreatic islet development. PLoS Biol 5: e203, 2007.

28. Zhang H, Mishra A, Chintagari NR, Gou D and Liu L: Micro-RNA-375 inhibits lung surfactant secretion by altering cytoskeleton reorganization. IUBMB Life 62: 78-83, 2010.

29. Cao L, Kong LP, Yu ZB, Han SP, Bai YF, Zhu J, Hu X, Zhu C, Zhu $\mathrm{S}$ and Guo XR: microRNA expression profiling of the developing mouse heart. Int J Mol Med 30: 1095-1104, 2012.

30. Adams JM and Cory S: The Bcl-2 protein family: Arbiters of cell survival. Science 281: 1322-1326, 1998.

31. Golestani Eimani B, Sanati MH, Houshmand M, Ataei M, Akbarian $\mathrm{F}$ and Shakhssalim N: Expression and prognostic significance of bcl-2 and bax in the progression and clinical outcome of transitional bladder cell carcinoma. Cell J 15: 356-363, 2014.

32. Oltvai ZN, Milliman CL and Korsmeyer SJ: Bcl-2 heterodimerizes in vivo with a conserved homolog, Bax, that accelerates programmed cell death. Cell 74: 609-619, 1993.

33. van der Heyden MA and Defize LH: Twenty one years of P19 cells: What an embryonal carcinoma cell line taught us about cardiomyocyte differentiation. Cardiovasc Res 58: 292-302, 2003.

34. van der Heyden MA, van Kempen MJ, Tsuji Y, Rook MB, Jongsma HJ and Opthof T: P19 embryonal carcinoma cells: A suitable model system for cardiac electrophysiological differentiation at the molecular and functional level. Cardiovasc Res 58 410-422, 2003.

35. Qin DN, Qian L, Hu DL, Yu ZB, Han SP, Zhu C, Wang X and $\mathrm{Hu}$ X: Effects of miR-19b overexpression on proliferation, differentiation, apoptosis and $\mathrm{Wnt} / \beta$-catenin signaling pathway in P19 cell model of cardiac differentiation in vitro. Cell Biochem Biophys 66: 709-722, 2013.
36. Zhu C, Hu DL, Liu YQ, Zhang QJ, Chen FK, Kong XQ, Cao KJ, Zhang JS and Qian LM: Fabp3 inhibits proliferation and promotes apoptosis of embryonic myocardial cells. Cell Biochem Biophys 60: 259-266, 2011

37. Zhu S, Hu X, Han S, Yu Z, Peng Y, Zhu J, Liu X, Qian L, Zhu C, Li M, et al: Differential expression profile of long non-coding RNAs during differentiation of cardiomyocytes. Int $\mathrm{J}$ Med Sci 11: 500-507, 2014

38. Yuan S, Zaidi S and Brueckner M: Congenital heart disease: Emerging themes linking genetics and development. Curr Opin Genet Dev 23: 352-359, 2013

39. Staudt D and Stainier D: Uncovering the molecular and cellular mechanisms of heart development using the zebrafish. Annu Rev Genet 46: 397-418, 2012.

40. Olson EN: Gene regulatory networks in the evolution and development of the heart. Science 313: 1922-1927, 2006.

41. Penton AL, Leonard LD and Spinner NB: Notch signaling in human development and disease. Semin Cell Dev Biol 23: 450-457, 2012

42. de la Pompa JL: Notch signaling in cardiac development and disease. Pediatr Cardiol 30: 643-650, 2009.

43. McDaniell R, Warthen DM, Sanchez-Lara PA, Pai A, Krantz ID, Piccoli DA and Spinner NB: NOTCH2 mutations cause Alagille syndrome, a heterogeneous disorder of the notch signaling pathway. Am J Hum Genet 79: 169-173, 2006.

44. Kamath BM, Spinner NB, Emerick KM, Chudley AE, Booth C, Piccoli DA and Krantz ID: Vascular anomalies in Alagille syndrome: A significant cause of morbidity and mortality. Circulation 109: 1354-1358, 2004.

45. Garg V, Muth AN, Ransom JF, Schluterman MK, Barnes R, King IN, Grossfeld PD and Srivastava D: Mutations in NOTCH1 cause aortic valve disease. Nature 437: 270-274, 2005.

46. Zhou XL and Liu JC: Role of Notch signaling in the mammalian heart. Braz J Med Biol Res 47: 1-10, 2014. 